\title{
PROJEÇÃO DIAMÉTRICA POR RAZÃO DE MOVIMENTAÇÃO EM UM FRAGMENTO DE FLORESTA OMBRÓFILA MISTA NO SUL DO PARANÁ
}

\author{
Mayara Dalla Lana ${ }^{1}$, Sylvio Péllico Netto ${ }^{2}$, Ana Paula Dalla Corte ${ }^{2}$, Carlos Roberto Sanquetta ${ }^{2}$, \\ Carlos Frederico Lins e Silva Brandão ${ }^{1}$ \\ ${ }^{1}$ Universidade Federal Rural de Pernambuco, Programa de Pós-Graduação em Ciências Florestais, Recife, Pernambuco, Brasil - \\ mayaradallalana@hotmail.com; cflsbrandao@hotmail.com \\ ${ }^{2}$ Universidade Federal do Paraná, Departamento de Ciências Florestais, Curitiba, Paraná, Brasil - sylviopelliconetto@ gmail.com; \\ anapaulacorte@gmail.com; carlos_sanquetta@ hotmail.com
}

Recebido para publicação: 11/03/2013 - Aceito para publicação: 21/04/2014

\begin{abstract}
Resumo
O objetivo deste estudo foi simular o crescimento em número de árvores e área basal de um fragmento de Floresta Ombrófila Mista, em nível de floresta, espécies e famílias botânicas de maior valor de importância. Os dados utilizados são provenientes de um inventário contínuo de três parcelas implantadas em 1995 de 1 ha cada e uma de 0,5 ha, totalizando uma área amostral de 3,5 ha, no município de São João do Triunfo, Paraná. Todos os indivíduos arbóreos com diâmetro à altura do peito igual ou maior que $10,0 \mathrm{~cm}$ foram identificados, mensurados, e durante as remedições, todas as árvores mortas e recrutadas foram registradas até o ano de 2011. As projeções com o modelo de razão de movimentação foram realizadas para os indivíduos arbóreos agrupados em intervalo de classe de $10 \mathrm{~cm}$ de diâmetro, para a prognose dos anos de 2013, 2015, 2017 e 2019. A floresta como um todo crescerá $5,7 \mathrm{~m}^{2} \cdot \mathrm{ha}^{-1}$ em área basal, mas não em número de árvores, confirmando amadurecimento desse fragmento.

Palavras-chave: Manejo sustentável; floresta nativa; área basal.
\end{abstract}

\begin{abstract}
Diametric projection by movement ratio in a Mixed Ombrophilous Forest fragment in Southern Paraná. The aim of this research was to simulate the growth in number of trees and basal area of a Mixed Ombrophilous Forest fragment, in level of forest, botanical families and species with the greater importance value. The data are from a continuous inventory in three sample plots of 1 ha each, and one of 0.5 ha, adding up 3.5 ha of sampled area, in São João do Triunfo, Paraná. All trees with diameter at breast height equal or greater than $10.0 \mathrm{~cm}$ were identified, measured and, during remeasurements, all recruited and dead trees were counted until the year 2011. The projections with movement ratio model were performed to the individual trees grouped in classes' interval of $10 \mathrm{~cm}$ diameter for the prognosis of the years 2013, 2015, 2017 and 2019. The forest as a whole will grow 5,7 $\mathrm{m}^{2}$.ha $\mathrm{a}^{-1}$ in basal area, but not in number of trees, confirming maturation of this fragment.
\end{abstract}

Keywords: Sustainable management; native forest; basal area.

\section{INTRODUÇÃO}

A relação do homem com as florestas começou antes dos primeiros registros históricos, mas nessa época era difícil entender que a floresta representasse para o homem um recurso valioso. Para as sociedades primitivas, a floresta era um elemento do ambiente com poucas oportunidades de uso, embora sobrevivessem de seus recursos. Hoje em dia, a floresta é tratada como um recurso escasso com valor agregado, pelos aspectos econômico, ecológico e social envolvidos no processo de produção (SCHNEIDER, 2009), buscando-se o tão discutido manejo florestal sustentável.

As florestas nativas continuam sendo um desafio aos técnicos florestais, os quais buscam obter os conhecimentos adequados quanto ao seu comportamento, evolução, produção e crescimento (BOM,

FLORESTA, Curitiba, PR, v. 45, n. 1, p. 151 - 162, jan. / mar. 2015.

Dala Lana, M. D. et al.

ISSN eletrônico 1982-4688 / ISSN impresso 0015-3826 
1996). Cada maciço florestal tem um incremento específico, variando de região para região, em função da topografia, do clima, dos solos e da sua utilização em períodos anteriores (FISCHER, 1987).

Apesar das grandes explorações sofridas no passado e das várias medidas adotadas para a recuperação e preservação, os remanescentes de Floresta Ombrófila Mista poderiam ser manejados para fornecer, entre outros bens e serviços para a população, madeira para fins industriais. Há espécies nessa tipologia florestal que apresentam padrões de crescimento condizentes para a exploração de madeira.

Segundo Hosokawa et al. (1998), para que haja aproveitamento racional e sobrevivência das florestas, é necessária a aplicação de técnicas silviculturais adequadas, baseada na ecologia de cada tipo de formação florestal. No que diz respeito à implantação de projetos de manejo florestal em florestas nativas e o seu aproveitamento permanente, é necessário que se conheça a sua composição e a sua estrutura. O conhecimento das características estruturais implica o conhecimento das espécies constituintes, suas exigências ecológicas, quantidades, distribuição e dimensões que permitam alteração positiva no povoamento.

Scolforo et al. (1996) enfatizam que, além de estudos de estrutura e dinâmica das florestas, é importante também conhecer o ciclo de corte e de como o número de árvores por classe de diâmetro evolui ao longo do tempo. Segundo Schneider e Finger (2000), é necessária a determinação da taxa de corte sustentada para o manejo das florestas naturais, bem como a criteriosa avaliação da estrutura da floresta.

Nesse sentido, a razão de movimentação é um importante modelo utilizado para a prognose em florestas nativas, sendo definida como a proporção de árvores que avançaram no lado direito das classes de diâmetro. Essa metodologia utiliza o incremento diamétrico médio e assume que a distribuição dos diâmetros é uniforme dentro dessas classes (HUSCH et al., 1982; SCOLFORO, 1998).

Saber com exatidão o que irá acontecer no futuro dentro de uma floresta nativa é impossível, visto que a dinâmica que nela ocorre é intensa e instável, muito influenciada pelas alterações que ocorrem no ambiente. Essas condicionantes não impedem que sejam realizadas prognoses do desenvolvimento das florestas, principalmente em relação ao crescimento das árvores.

Pelo exposto, o objetivo deste estudo foi simular o crescimento em número de árvores e área basal de um fragmento de Floresta Ombrófila Mista em nível de floresta e de espécies e famílias botânicas de maior valor de importância, utilizando o método de razão de movimentação, para um fragmento de Floresta Ombrófila Mista no município de São João do Triunfo, Paraná.

\section{MATERIAL E MÉTODOS}

\section{Descrição da área de estudo}

A área de estudo é a Estação Experimental Rudi Arno Seitz, da Universidade Federal do Paraná, com aproximadamente 32 ha, localizada no município de São João do Triunfo, região centro-sul do estado do Paraná, distando aproximadamente $125 \mathrm{~km}$ de Curitiba (Figura 1).

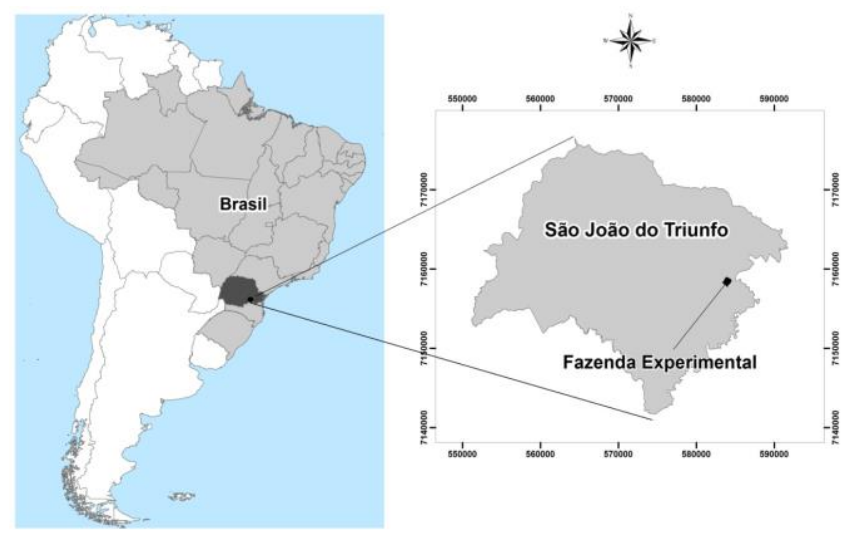

Figura 1. Localização da Estação Experimental Rudi Arno Seitz no município de São João do Triunfo, no estado do Paraná, Brasil.

Figure 1. Location of Estação Experimental Rudi Arno Seitz in municipality of São João do Triunfo, in State of Paraná, Brazil. 
O clima da região é do tipo $\mathrm{Cfb}$, segundo a classificação climática de Köppen, sendo temperado sempre úmido, com temperatura média anual de 17 a $18{ }^{\circ} \mathrm{C}$. A umidade relativa anual varia de 75 a $85 \%$ e a evapotranspiração média anual é de 800 a $900 \mathrm{~mm}$. A precipitação anual média, de acordo com as séries contínuas de dados diários dentro de um período homogêneo compreendido entre 1972 e 1998, varia de 1400 a $1600 \mathrm{~mm}$ (IAPAR, 2012). A altitude é de $780 \mathrm{~m}$.

Os solos dessa região compõem-se de associações de ARGISSOLOS VERMELHOAMARELO, CAMBISSOLOS HÁPLICOS Tb e LATOSSOLOS VERMELHOS ambos Distróficos, de acordo com o Sistema Brasileiro de Classificação de Solos (EMBRAPA, 2006).

A vegetação da área de estudo pertence a um fragmento de Floresta Ombrófila Mista, também chamada de Floresta com Araucária. A composição florística dessa tipologia florestal é caracterizada pela associação da araucária com grupos diferenciados de espécies.

\section{Obtenção dos dados}

Os dados utilizados neste trabalho são provenientes de um inventário contínuo de 4 parcelas permanentes (3,5 ha), que foram medidas anualmente, sempre no mês de julho, entre os anos de $1995 \mathrm{e}$ 2011. Três parcelas possuem uma área de 1 ha cada, de forma quadrada (100 x $100 \mathrm{~m})$, e a quarta parcela possui uma área de aproximadamente 0,5 há, de forma irregular, devido à presença de um rio que margeia um dos seus lados.

Todos os indivíduos arbóreos com diâmetro à altura do peito igual ou maior a $10 \mathrm{~cm}$ $(\mathrm{DAP} \geq 10 \mathrm{~cm})$ foram identificados, numerados e etiquetados em 1995. As árvores foram medidas utilizando-se fita métrica (precisão de $\mathrm{mm}$ ) e pintadas na altura do DAP com tinta azul, visando padronizar o local da medição. Nas remedições a cada ano, foram inseridas no banco de dados as árvores recrutas, ou seja, as que atingiram o DAP mínimo estipulado $(10 \mathrm{~cm})$ e também as árvores mortas e caídas.

Para este estudo, foram utilizadas apenas as informações referentes aos anos de 2009 e 2011, visto que, segundo Dalla Lana (2013), o modelo mais adequado para as projeções nesse fragmento de floresta é o da razão de movimentação para amplitudes temporais de 2 anos. Os diâmetros de cada um desses anos foram agrupados, respectivamente, em classes com intervalos de $10 \mathrm{~cm}$ a partir do diâmetro mínimo de $10 \mathrm{~cm}$.

O recrutamento e a mortalidade não foram modelados para a prognose. Logo, para o número de árvores recrutadas, utilizaram-se as informações do número de árvores que não constavam em 2009 e que atingiram o DAP mínimo de $10 \mathrm{~cm}$ em 2010 ou 2011. Já para a mortalidade, foi considerado o número de árvores medidas no ano inicial e que tiveram sua morte verificada durante esses anos.

\section{Projeções diamétricas}

A prognose foi realizada para os anos de 2013, 2015, 2017 e 2019 (múltiplos do intervalo de 2 anos), em três níveis, segundo inventário fitossociológico de 2011: (1) Floresta - considerando todos os indivíduos arbóreos presentes nas quatro parcelas; (2) Famílias botânicas de maior valor de importância Lauraceae e Myrtaceae; (3) Espécies de maior valor de importância - Araucaria angustifolia (Bertol.) O. Kuntze, Nectandra grandiflora Ness \& C. Mart. Ex Ness, Matayba elaeagnoides Radlk. e Ilex paraguariensis A. St.-Hil.

Para o cálculo das projeções, foram feitas as proporções de árvores que passam de uma classe diamétrica para outra, chamada de razão de movimentação, dada pela expressão (1) (SCOLFORO, 1998):

$$
m=\frac{\overline{I P D}_{i}}{\Delta D} * 100
$$

em que: $m=$ razão de movimentação;

$\overline{I P D}_{j}=$ incremento periódico médio em diâmetro da $j$-ésima classe de diâmetro;

$\Delta D=$ intervalo de classe de diâmetro.

O incremento periódico médio, por classe diamétrica, é obtido pela expressão (2):

$$
\overline{I P D}_{j}=\frac{\sum_{i=1}^{n}\left(D A P_{2 i}-D A P_{1 i}\right)}{N}
$$

FLORESTA, Curitiba, PR, v. 45, n. 1, p. 151 - 162, jan. / mar. 2015.

Dala Lana, M. D. et al.

ISSN eletrônico 1982-4688 / ISSN impresso 0015-3826

153

DOI: 10.5380/rf.v45i1.31091 
em que: $\overline{I P D}_{j}=$ incremento periódico médio em diâmetro da $j$-ésima classe de diâmetro;

$D A P_{1 i}=$ DAP da $i$-ésima árvore na $1^{\circ}$ medição;

$D A P_{2 i}=$ DAP da $i$-ésima árvore na $2^{\circ}$ medição;

$N=$ número total de árvores em cada classe diamétrica.

Segundo Scolforo (1998), para que a prognose por esse método seja realizada, é necessário: relacionar o número de árvores por hectare e por classes de diâmetro para o tempo $t+1$; definir o incremento periódico médio de cada classe diamétrica; calcular a razão de movimentação; e, por último, somar e subtrair, respectivamente, a taxa de recrutamento e de mortalidade por classe de diâmetro.

Para a comparação das prognoses, foram construídos os histogramas de frequência do número de árvores observado em 2011 e estimado para o ano de 2019. Também foram feitas as estimativas da área basal por hectare $(\mathrm{G})$, com base no número de árvores estimado em cada um dos anos (2013, 2015, 2017 e 2019) e seus respectivos centros de classe.

\section{RESULTADOS E DISCUSSÃO}

\section{Projeção diamétrica da floresta}

Os indivíduos presentes nessa floresta foram divididos em 9 classes, com intervalos de $10 \mathrm{~cm}$ cada, sendo que a última classe abrangeu todos os indivíduos maiores que $90 \mathrm{~cm}$ de DAP.

As prognoses pela razão de movimentação para a floresta apontaram um aumento do número de árvores de 8,1 árv.ha ${ }^{-1}$, passando de 781,7 árv.ha ${ }^{-1}$ para 789,8 árv.ha ${ }^{-1}$ no período entre 2011 e 2019. Esse aumento corresponde à expectativa de recrutamento de apenas 1 árv.ha ${ }^{-1}$.ano ${ }^{-1}$ dentro desse fragmento (Tabela 1). Quando comparamos esse resultado ao recrutamento ocorrido entre os anos de 1995 e 2011, observa-se que houve uma redução de aproximadamente 6 árv.ha ${ }^{-1} \cdot$ ano $^{-1}$, já que, segundo inventário fitossociológico (DALLA LANA, 2013), nesse intervalo de tempo (1995-2011) houve o recrutamento de 116 árv.ha ${ }^{-1}$, ou seja, 7,2 árv.ha ${ }^{-1} \cdot$ ano $^{-1}$.

Tabela 1. Número de árvores por hectare, observadas em 2011 e estimadas pela razão de movimentação em 2013, 2015, 2017 e 2019, no fragmento de Floresta Ombrófila Mista, em São João do Triunfo, Paraná.

Table 1. Number of trees per hectare, observed in 2011 and estimated by the movement ratio in 2013, 2015, 2017 and 2019, in a Mixed Ombrophilous Forest fragment, in São João do Triunfo, Paraná.

\begin{tabular}{lccccc}
\hline $\mathbf{C C}$ & $\mathbf{2 0 1 1}$ & $\mathbf{2 0 1 3}$ & $\mathbf{2 0 1 5}$ & $\mathbf{2 0 1 7}$ & $\mathbf{2 0 1 9}$ \\
\hline 15 & 497,1 & 479,8 & 471,5 & 463,5 & 455,7 \\
25 & 138,3 & 152,5 & 158,8 & 164,6 & 169,8 \\
35 & 61,1 & 64,0 & 65,8 & 67,8 & 69,9 \\
45 & 39,4 & 40,2 & 40,6 & 41,1 & 41,7 \\
55 & 25,4 & 25,3 & 25,3 & 25,4 & 25,4 \\
65 & 9,1 & 10,8 & 11,5 & 12,2 & 12,8 \\
75 & 7,7 & 8,0 & 8,2 & 8,4 & 8,7 \\
85 & 1,7 & 2,6 & 3,0 & 3,4 & 3,9 \\
$>90$ & 1,7 & 1,7 & 1,8 & 1,9 & 2,0 \\
\hline Total & 781,7 & 784,9 & 786,6 & 788,2 & 789,8 \\
\hline
\end{tabular}

CC: centro de classe de diâmetro.

Ebling (2012), estudando as projeções diamétricas para um fragmento de Floresta Ombrófila Mista de 10 ha em São Francisco de Paula, no Rio Grande do Sul, usou razão de movimentação e estimou uma redução de 4,3 árv.ha ${ }^{-1}$ entre os anos de 2009 e 2021. Stepka et al. (2010) também estimaram uma redução de em média 10 árv.ha ${ }^{-1}$, utilizando a prognose por razão de movimentação com intervalos de $3 \mathrm{e}$ 6 anos, entre 2008 e 2014, em um fragmento de Floresta Ombrófila Mista de 25 ha em Irati, Paraná.

A maioria das classes diamétricas seguiu a tendência de aumento, com exceção da primeira classe, que apresentou uma redução de $8 \%$ do número de árvores em relação a 2011, passando de 497,1 árv.ha ${ }^{-1}$ para 455,7 árv.ha ${ }^{-1}$. Essa redução é explicada pela diminuição do recrutamento e aumento do crescimento, fazendo com que as árvores dessa classe migrem para as de maior diâmetro. 
A distribuição diamétrica da floresta apresentou forma decrescente durante os anos de prognose. Esse padrão é característico das espécies pertencentes às florestas inequiâneas (ASSMANN, 1970) e que apresentam boa regeneração, com grande concentração de indivíduos nas classes inferiores (Figura 2a).

A prognose da área basal resultou em uma perspectiva de crescimento para os próximos anos, passando de 41,7 $\mathrm{m}^{2} \cdot \mathrm{ha}^{-1}$ em 2011 para 47,4 $\mathrm{m}^{2} \cdot \mathrm{ha}^{-1}$ em 2019, aumento de 5,7 $\mathrm{m}^{2}$.ha ${ }^{-1}$ (Figura 2b). Essa tendência é atribuída ao crescimento das árvores, que ocasiona a grande movimentação entre as classes de diâmetro, já que o recrutamento projetado é de somente 1 árv.ha ${ }^{-1}$.ano ${ }^{-1}$, não influenciando tanto nesse aumento em área basal.

Com base nas análises passadas (anos de 1995 a 2011) e considerando as perspectivas futuras (projeções entre os anos de 2011 e 2019), pode-se dizer que o crescimento da floresta alcançará o estocamento ou amadurecimento, visto que a prognose com base na razão de movimentação infere sobre um pequeno acréscimo do número de árvores recrutadas e um maior crescimento dos indivíduos dessa floresta.
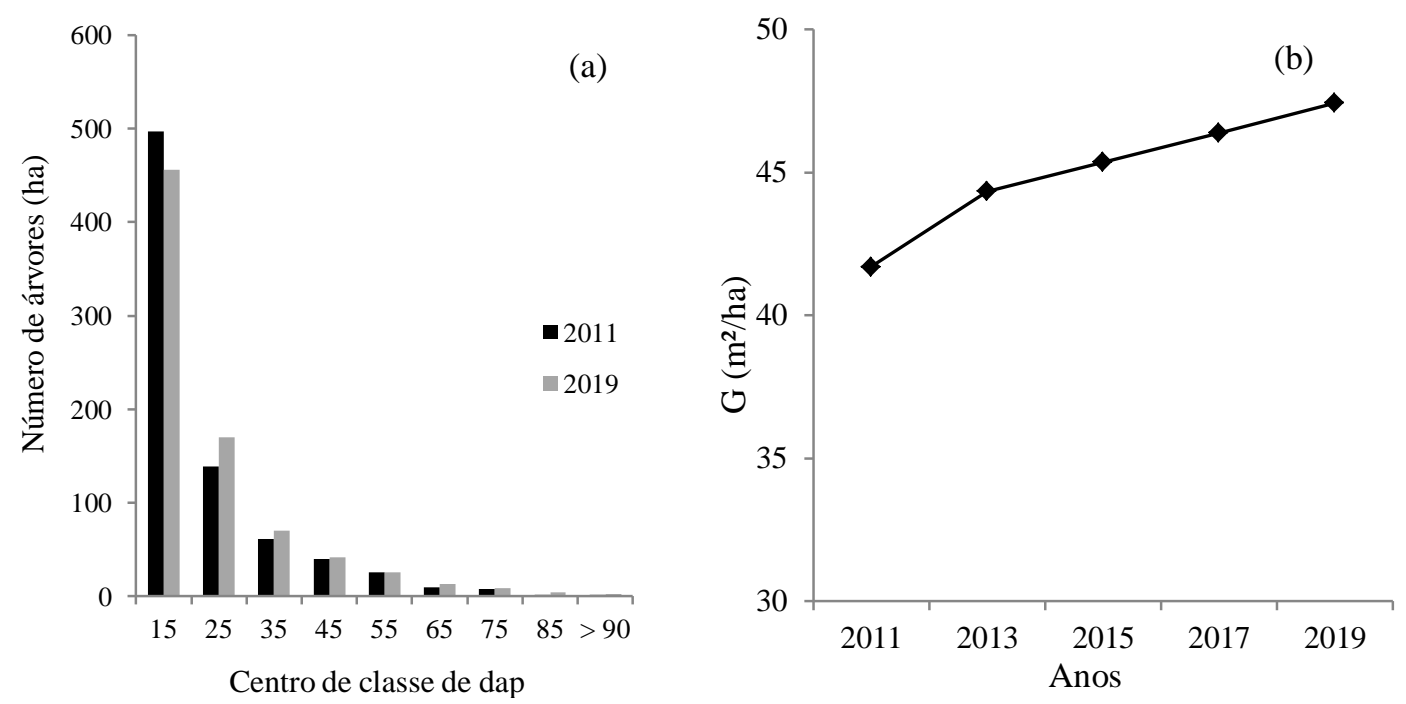

Figura 2. Número de árvores por hectare observada em 2011 e projetada para 2019 (a) e área basal observada em 2011 e estimada para os anos de 2013, 2015, 2017 e 2019 (b), em fragmento de Floresta Ombrófila Mista em São João do Triunfo, Paraná.

Figure 2. Number of trees per hectare observed in 2011 and projected to 2019 (a) and observed basal area in 2011 and estimated for 2013, 2015, 2017 and 2019 (b), in a Mixed Ombrophilous Forest fragment, in São João do Triunfo, Paraná.

Segundo Schneider (2009), para que uma floresta forneça produtos madeireiros e não madeireiros às gerações atuais e futuras em igual quantidade e qualidade, há que se cortar periodicamente apenas uma quantidade de madeira igual ao crescimento das árvores da floresta. Sendo assim, ao considerar viável para o aproveitamento madeireiro árvores com diâmetro superiores a $40 \mathrm{~cm}$, observa-se na tabela 1 que no ano de 2011 esse fragmento apresentou 85 árv.ha $^{-1}$ com diâmetros superiores a $40 \mathrm{~cm}$ e, pela prognose por razão de movimentação, em 2019 teria 94,5 árv.ha ${ }^{-1}$ com dimensões superiores a esse valor. Logo, haveria, em 2019, 9,5 árv.ha ${ }^{-1}$ passíveis de corte em regime de manejo sustentado.

Para que isso realmente ocorra, as taxas de crescimento devem permanecer semelhantes às estimadas pela prognose por razão de movimentação, mas essas taxas podem ser alteradas, principalmente, por fatores ambientais, como o clima, por exemplo, que não pode ser controlado, podendo influenciar no número final de árvores passíveis de corte.

\section{Projeção diamétrica para as espécies de maior valor de importância}

Araucaria angustifolia, Ilex paraguariensis, Matayba elaeagnoides e Nectandra grandiflora pertencem às famílias Araucariaceae, Aquifoliaceae, Sapindaceae e Lauraceae, respectivamente, sendo as espécies que apresentaram maiores valores de importância nos anos de 1995 e 2011 nesse fragmento

FLORESTA, Curitiba, PR, v. 45, n. 1, p. 151 - 162, jan. / mar. 2015. 
(DALLA LANA, 2013). Na tabela 2 podem ser visualizadas as projeções por meio da razão de movimentação para cada uma dessas espécies.

Entre os anos de 2011 e 2019, a espécie Araucaria angustifolia apresentará redução do número total de árvores, passando de 160,9 árv.ha ${ }^{-1}$ para 154,5 árv.ha ${ }^{-1}$. Essa redução é mais acentuada na primeira classe diamétrica, devido ao baixo recrutamento e à alta mortalidade, resultado que já havia sido percebido pela análise fitossociológica entre os anos do inventário (DALLA LANA, 2013).

Tabela 2. Número de árvores, por hectare, observadas em 2011(I) e estimadas pela razão de movimentação em 2013(II), 2015(III), 2017(IV) e 2019(V), para as espécies de maior valor de importância em fragmento de Floresta Ombrófila Mista em São João do Triunfo, Paraná.

Table 2. Number of trees per hectare, observed in 2011(I) and estimated by the movement ratio in 2013(II), 2015(III), 2017(IV) and 2019(V), in a Mixed Ombrophilous Forest fragment, in São João do Triunfo, Paraná.

\begin{tabular}{|c|c|c|c|c|c|c|c|c|c|c|c|c|c|c|c|c|c|c|c|c|}
\hline \multirow{2}{*}{$\mathrm{CC}$} & \multicolumn{5}{|c|}{ Araucaria angustifolia } & \multicolumn{5}{|c|}{ Ilex paraguariensis } & \multicolumn{5}{|c|}{ Matayba elaeagnoides } & \multicolumn{5}{|c|}{ Nectandra grandiflora } \\
\hline & $\mathbf{I}$ & II & III & IV & $\mathbf{V}$ & $\mathbf{I}$ & II & III & IV & $\mathbf{V}$ & $\mathbf{I}$ & II & III & IV & $\mathbf{V}$ & $\mathbf{I}$ & II & III & IV & $\mathbf{V}$ \\
\hline 15 & 38,9 & 36,9 & 35,8 & 34,8 & 33,7 & 43,4 & 41,2 & 40,8 & 40,4 & 40,0 & 14,0 & 13,8 & 13,6 & 13,5 & 13,4 & 85,4 & 85,2 & 86,2 & 87,1 & 88,1 \\
\hline 25 & 30,9 & 29,8 & 29,3 & 28,7 & 28,2 & 4,6 & 6,4 & 7,4 & 8,3 & 9,1 & 11,1 & 11,5 & 11,7 & 11,9 & 12,0 & 15,4 & 17,5 & 19,3 & 21,1 & 22,8 \\
\hline 35 & 29,1 & 28,8 & 28,2 & 27,5 & 26,8 & 0,0 & 0,2 & 0,3 & 0,3 & 0,4 & 8,0 & 7,4 & 7,1 & 6,8 & 6,6 & 2,6 & 3,6 & 4,3 & 5,1 & 6,0 \\
\hline 45 & 26,3 & 25,3 & 25,2 & 25,2 & 25,1 & - & - & - & - & - & 3,4 & 3,5 & 3,6 & 3,7 & 3,8 & 0,3 & 0,7 & 0,8 & 0,9 & 1,1 \\
\hline 55 & 20,3 & 19,7 & 19,6 & 19,5 & 19,4 & - & - & - & - & - & 0,9 & 0,9 & 0,9 & 1,0 & 1,0 & 0,9 & 0,6 & 0,7 & 0,7 & 0,8 \\
\hline 65 & 6,9 & 9,1 & 9,7 & 10,3 & 10,8 & - & - & - & - & - & 0,3 & 0,3 & 0,3 & 0,4 & 0,4 & 0,3 & 0,3 & 0,3 & 0,4 & 0,4 \\
\hline 75 & 6,9 & 6,0 & 6,1 & 6,3 & 6,6 & - & - & - & - & - & - & - & - & - & - & - & - & - & - & - \\
\hline 85 & 1,4 & 1,9 & 2,2 & 2,6 & 2,9 & - & - & - & - & - & - & - & - & - & - & - & - & - & - & - \\
\hline$>90$ & 0,3 & 0,5 & 0,6 & 0,7 & 0,9 & - & - & - & - & - & - & - & - & - & - & - & - & - & - & - \\
\hline Total & 161 & 158 & 157 & 156 & 155 & 48 & 48 & 48 & 49 & 49 & 38 & 37 & 37 & 37 & 37 & 105 & 108 & 112 & 115 & 119 \\
\hline
\end{tabular}

CC: centro de classe de diâmetro.

O decréscimo no número de árvores projetadas também se mantém nas classes de 25, 35, 45 e $55 \mathrm{~cm}$. Nas classes subsequentes, ocorre o inverso: há um aumento no número de indivíduos em cada classe durante os anos. Esse resultado pode ser atribuído ao provável crescimento das árvores de maiores diâmetros, que, em sua maioria, estão em uma situação privilegiada em relação às demais, já que atingiram o dossel superior da floresta e não sofrem mais concorrência entre indivíduos.

Sanquetta e Mattei (2006) sugerem a necessidade de distúrbios na FOM para que a Araucaria angustifolia possa se regenerar, já que é pouco tolerante à sombra, principalmente na fase juvenil. A criação de um ambiente lumínico favorável para a germinação e desenvolvimento de plântulas dessa espécie seria uma estratégia de mantê-la dentro da floresta futuramente. $\mathrm{O}$ aumento no crescimento das árvores de maiores diâmetros, mesmo com a redução do número total, durante os 8 anos de prognoses, corrobora a estimativa da área basal, que aumentará, passando de $20,1 \mathrm{~m}^{2} \cdot \mathrm{ha}^{-1}$ (2011) para 21,9 m².ha ${ }^{-1}$ (2019), com um incremento de cerca de $0,2 \mathrm{~m}^{2} \cdot \mathrm{ha}^{-1}$. ano ${ }^{-1}$ (Figura 3 ).

Para Ilex paraguariensis, na prognose pela razão de movimentação, estima-se que nos próximos 8 anos haja um aumento de apenas 1,5 árv.ha ${ }^{-1}$ no número total de indivíduos. Na primeira classe de diâmetro, ocorrerá uma diminuição do número de árvores. Já na segunda, um aumento e, com isso, o surgimento de uma terceira classe $(30-40 \mathrm{~cm})$ que não existia anteriormente, mostrando que essa espécie está em fase de evolução na floresta. Essa dinâmica está vinculada ao baixo recrutamento e ao crescimento das árvores, que acabam por aumentar a movimentação entre classes.

Apesar da previsão do aumento do número de árvores, a área basal estimada para a erva-mate terá um acréscimo pequeno durante os 8 anos, passando de $0,9 \mathrm{~m}^{2} \cdot \mathrm{ha}^{-1}$ para $1,2 \mathrm{~m}^{2} \cdot \mathrm{ha}^{-1}$ (Figura 3). Esse resultado não está necessariamente vinculado ao baixo crescimento, embora a espécie possua um número elevado de indivíduos, mas porque eles possuem pequenas dimensões, que não permitem um ganho elevado em área basal.

As projeções para Matayba elaeagnoides até 2019 retratam uma leve redução e praticamente uma estagnação quanto ao número de árvores total, não havendo uma dinâmica considerável dessa espécie dentro da floresta. Em relação à movimentação entre as classes diamétricas, ocorre uma diminuição do número de árvores na primeira e terceira classes. Nas restantes, ocorre um aumento, sendo 
pouco significativas. Na figura 3 fica mais clara a estagnação dessa espécie no tempo. A estimativa da área basal é constante de 2011 até 2019. Isso é devido ao fato de as taxas de recrutamento e mortalidade serem praticamente iguais e à baixa capacidade de crescimento da espécie dentro desse fragmento de floresta, com uma média de $0,18 \mathrm{~cm} \cdot \mathrm{cno}^{-1}$, conforme relatado em estudo sobre o seu crescimento (DALLA LANA, 2013). Outros estudos, como de Schaaf et al. (2005) e Canetti et al. (2014), também descrevem essa espécie com baixo crescimento anual em diâmetro em fragmentos de Floresta Ombrófila Mista, com, respectivamente, 0,17 e $0,08 \mathrm{~cm} \cdot \mathrm{ano}^{-1}$.

Ao contrário do que foi observado nas demais espécies, a projeção para Nectandra grandiflora apresentará um aumento considerável em relação ao número total de indivíduos. Em 2011 havia 104,9 árv.ha ${ }^{-1}$, e no ano de 2019 o valor projetado foi de 119,1 árv.ha ${ }^{-1}$ (aumento de 14,2 árv.ha ${ }^{-1}$ ). Corroborando com isso pode-se observar o aumento da área basal dessa espécie na figura 3 , passando de 2,5 $\mathrm{m}^{2} \cdot \mathrm{ha}^{-1}$ em 2011 para 3,7 $\mathrm{m}^{2} \cdot \mathrm{ha}^{-1}$ em 2019. Segundo Carvalho (2010), essa espécie é descrita na literatura como secundária tardia ou clímax tolerante a sombra, tolerando sombreamentos de baixa intensidade na fase juvenil e baixas temperaturas, características que podem contribuir para um maior crescimento nesse fragmento.
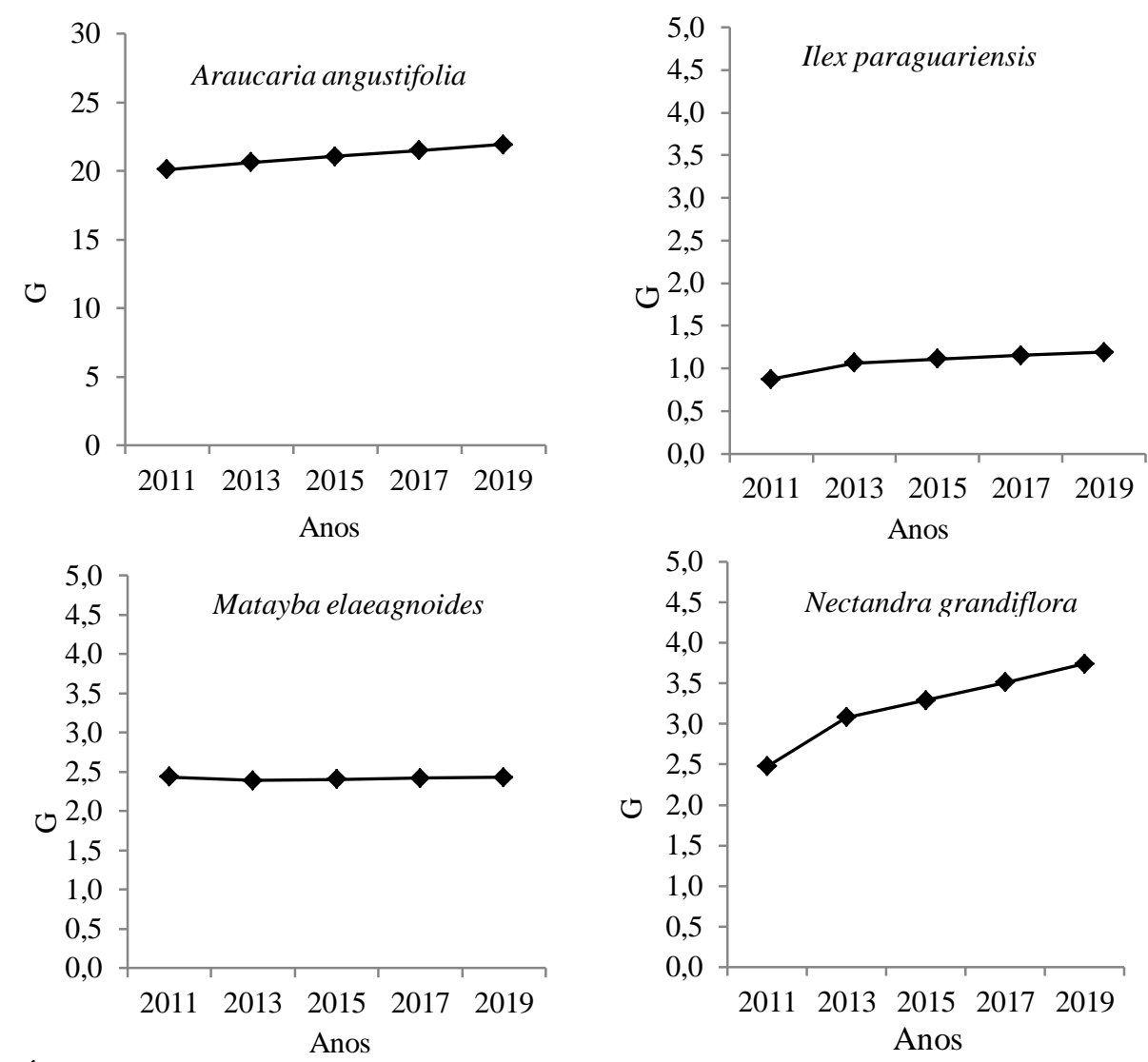

Figura 3. Área basal observada em 2011 e estimada para os anos de 2013, 2015, 2017 e 2019 para as espécies de maior valor de importância em fragmento de Floresta Ombrófila Mista em São João do Triunfo, Paraná.

Figure 3. Observed basal area in 2011 and estimated for 2013, 2015, 2017 and 2019 for the species of greater importance value, in a Mixed Ombrophilous Forest fragment, in São João do Triunfo, Paraná.

O padrão da distribuição diamétrica das quatro espécies de 2011 até 2019 também permaneceu igual ao da floresta com forma decrescente, ou de J-invertido (Figura 4). No entanto, Araucaria angustifolia apresenta uma tendência a não manter esse padrão de distribuição, visto que em 2019 as 
primeiras classes começam a ter uma frequência similar de indivíduos, devido ao baixo recrutamento. Se essa característica permanecer, são consideráveis as chances de que a araucária apresente, no futuro, distribuição diamétrica unimodal ou bimodal dentro dessa floresta. Machado et al. (2009) já relataram distribuição unimodal para Araucaria angustifolia em um fragmento de Floresta Ombrófila Mista, cuja área é de 15,2 ha, em Curitiba, Paraná.
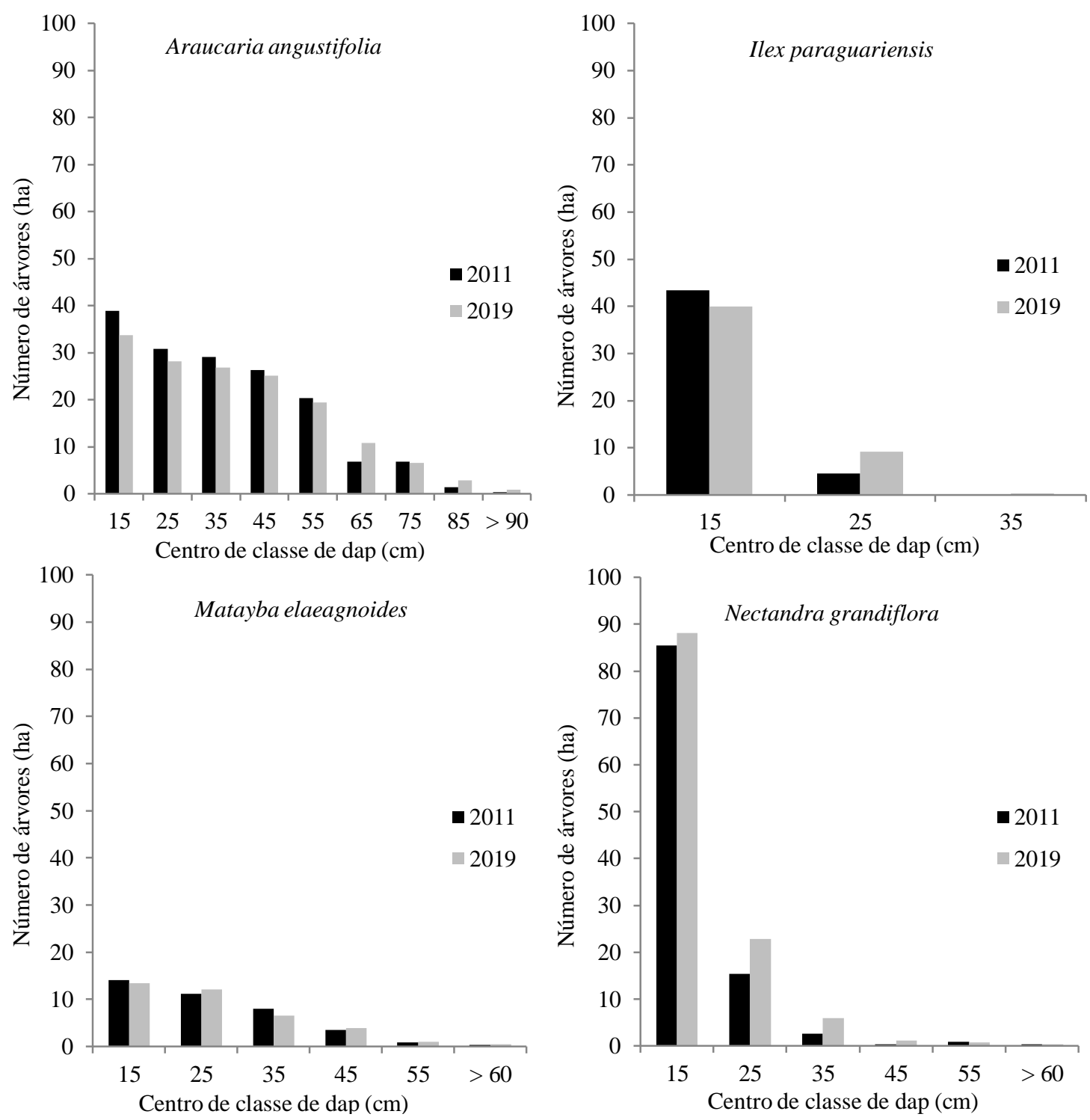

Figura 4. Número de árvores por hectare observado em 2011 e projetado para 2019 para as espécies de maior valor de importância em fragmento de Floresta Ombrófila Mista em São João do Triunfo, Paraná.

Figure 4. Number of trees per hectare observed in 2011 and projected for 2019 for the species of greater importance value, in a Mixed Ombrophilous Forest fragment, in São João do Triunfo, Paraná.

\section{Projeção diamétrica para as famílias botânicas Lauraceae e Myrtaceae}

As famílias botânicas Lauraceae e Myrtaceae apresentaram destaque dentro desse fragmento de Floresta Ombrófila Mista, devido à boa representatividade na composição florística e, principalmente, pelo potencial ecológico e em alguns casos madeireiros de certas espécies (DALLA LANA, 2013). 
Lauraceae é representada nessa floresta pelas seguintes espécies: Cinnamomum sellowianum (Ness \& Mart.) Kosterm., Cinnamomum vesiculosum (Ness) Kosterm., Nectandra grandiflora Ness \& C. Mart. ex Ness, Nectandra megapotamica (Spreng.) Mez, Nectandra sp. Rol. Ex Rottb., Ocotea porosa (Nees \& Mart.) Barroso, Ocotea puberula (Rich.) Nees, Ocotea pulchella Mart., Ocotea sp. e Persea major (Ness) L.E. Kopp. Myrtaceae é representada por: Blepharocalyx salicifolius (Kunth) O. Berg, Calyptranthes sp., Campomanesia guazumifolia (Cambess.) O. Berg., Campomanesia xanthocarpa (Mart.) O. Berg, Eugenia involucrata DC., Eugenia uniflora L., Myrcia palustris DC., Myrcia rostrata DC., Myrcia sp. e Psidium sp.

As projeções pela razão de movimentação dão indícios de que Lauraceae apresentará um aumento no número de árvores total dentro desse fragmento. $\mathrm{O}$ aumento será de aproximadamente 1,5 árv.ha ${ }^{-1} \cdot$ ano $^{-1}$, passando de 180,9 árv.ha ${ }^{-1}$ em 2011 para 191,7 árv.ha ${ }^{-1}$ em 2019 (Tabela 3). Ebling (2012), estudando a prognose por razão de movimentação para essa família em um fragmento de Floresta Ombrófila Mista no Rio Grande do Sul, relatou um aumento de apenas 0,5 árv.ha $^{-1}$. ano ${ }^{-1}$, valor inferior ao encontrado neste trabalho.

Tabela 3. Número de árvores, por hectare, observados em 2011 e estimados pela razão de movimentação em 2013, 2015, 2017 e 2019 para Lauraceae e Myrtaceae, em fragmento de Floresta Ombrófila Mista em São João do Triunfo, Paraná.

Table 3. Number of trees per hectare, observed in 2011 and estimated by the movement ratio in 2013, 2015, 2017 and 2019 to Lauraceae and Myrtaceae, in a Mixed Ombrophilous Forest fragment, in São João do Triunfo, Paraná.

\begin{tabular}{lcccccccccc}
\hline \multirow{2}{*}{ CC } & \multicolumn{3}{c}{ Lauraceae } & \multicolumn{5}{c}{ Myrtaceae } \\
\cline { 2 - 12 } & $\mathbf{2 0 1 1}$ & $\mathbf{2 0 1 3}$ & $\mathbf{2 0 1 5}$ & $\mathbf{2 0 1 7}$ & $\mathbf{2 0 1 9}$ & $\mathbf{2 0 1 1}$ & $\mathbf{2 0 1 3}$ & $\mathbf{2 0 1 5}$ & $\mathbf{2 0 1 7}$ & $\mathbf{2 0 1 9}$ \\
\hline 15 & 132,0 & 131,1 & 132,2 & 133,2 & 134,2 & 84,3 & 79,9 & 78,7 & 77,4 & 76,2 \\
25 & 29,1 & 30,7 & 33,2 & 35,7 & 38,1 & 12,9 & 14,4 & 15,5 & 16,6 & 17,6 \\
35 & 8,9 & 8,8 & 9,2 & 9,6 & 10,2 & 2,9 & 2,7 & 3,1 & 3,5 & 4,0 \\
45 & 5,4 & 5,2 & 5,0 & 4,8 & 4,6 & 0,9 & 0,9 & 0,9 & 1,0 & 1,0 \\
55 & 2,9 & 2,4 & 2,3 & 2,1 & 2,0 & - & - & - & - & - \\
65 & 1,1 & 1,2 & 1,3 & 1,3 & 1,3 & - & - & - & - & - \\
75 & 0,6 & 0,6 & 0,6 & 0,7 & 0,7 & - & - & - & - & - \\
85 & 0,9 & 0,8 & 0,7 & 0,7 & 0,6 & - & - & - & - & - \\
\hline Total & 180,9 & 180,7 & 184,4 & 188,1 & 191,7 & 100,9 & 98,0 & 98,3 & 98,5 & 98,8 \\
\hline CC: & & & & & & & & & &
\end{tabular}

CC: centro de classe de diâmetro.

Verifica-se que nas classes de 45 e $55 \mathrm{~cm}$ para Lauraceae ocorre uma redução no número de árvores, enquanto que nas demais classes há um aumento desse número, concordando com o total. Nas estimativas de área basal por hectare, ocorre um pequeno acréscimo, passando de $6,7 \mathrm{~m}^{2} \cdot \mathrm{ha}^{-1} \mathrm{em} 2011$ para 7,5 $\mathrm{m}^{2} \cdot \mathrm{ha}^{-1}$ em 2019 (Figura 5b). Esses resultados indicam que Lauraceae deverá manter o mesmo nível de importância já apresentado durante os anos anteriores, aumentando a sua dominância com o passar dos anos dentro dessa floresta, sendo essa uma informação importante no desenvolvimento de planos de manejo sustentáveis, já que, segundo Canalez et al. (2006), muitas espécies dessa família têm bom potencial silvicultural, com usos variados e valor econômico.

A família Myrtaceae apresentou padrões distintos quando comparada à Lauraceae. Em relação à prognose, a razão de movimentação estima que haja um pequeno decréscimo e, após, um acréscimo do número de árvores total durante os 8 anos, passando de 100,9 árv.ha ${ }^{-1}$ para 98,8 árv.ha ${ }^{-1}$, perda de 2,1 árv.ha ${ }^{-1}$ (Figura 5a). Para Klein (1984), a família Myrtaceae representa grande valor de importância dentro do sub-bosque das Florestas de Araucária, descrevendo um grande número de espécies e densidade.

Mesmo com a redução do número de árvores total, pela estimativa de crescimento em área basal, espera-se que em 2019 haja $2,8 \mathrm{~m}^{2} \cdot \mathrm{ha}^{-1}$, apenas $0,6 \mathrm{~m}^{2} \cdot \mathrm{ha}^{-1}$ a mais do que em 2011 , mostrando que essa família ganhará área transversal dentro da floresta, mas não há perspectivas de modificações intensas na sua estrutura durante os próximos 8 anos (Figura 5b). A baixa área basal dessa espécie está ligada ao tamanho das árvores dentro dessa família, já que seus diâmetros não ultrapassam $50 \mathrm{~cm}$, tendo cerca de

FLORESTA, Curitiba, PR, v. 45, n. 1, p. 151 - 162, jan. / mar. 2015.

Dala Lana, M. D. et al.

ISSN eletrônico 1982-4688 / ISSN impresso 0015-3826

DOI: $10.5380 /$ rf.v45i1.31091 
$80 \%$ dos indivíduos concentrados na primeira classe de DAP, ao contrário da Lauraceae, que possui diâmetros superiores a $50 \mathrm{~cm}$ e têm aproximadamente $30 \%$ de indivíduos nas classes maiores que $15 \mathrm{~cm}$.

Corroborando o que já foi descrito para a floresta como um todo e para as quatro espécies, a distribuição diamétrica das duas famílias analisadas é do tipo decrescente, com desaceleração gradual em todos os anos projetados, padrão das florestas multiâneas e mistas (Figura 5a).
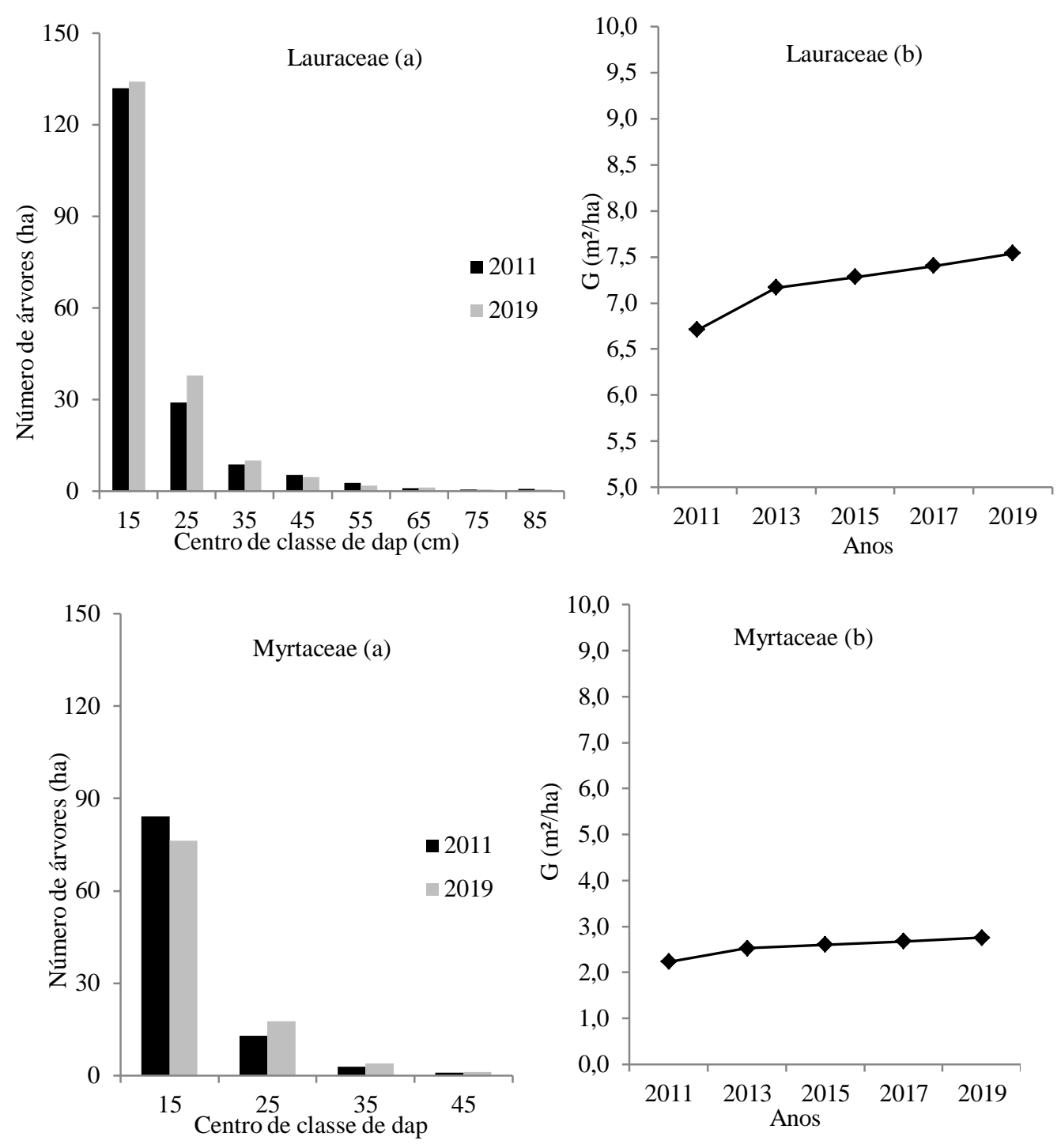

Figura 5. Número de árvores por hectare observado em 2011 e projetado para 2019 (a) e área basal observada em 2011 e estimada para os anos de 2013, 2015, 2017 e 2019 (b), para Lauraceae e Myrtaceae, em floresta Ombrófila Mista em São João do Triunfo, Paraná.

Figure 5. Number of trees per hectare observed in 2011 and projected for 2019 (a) and observed basal area in 2011 and estimated for 2013, 2015, 2017 and 2019 (b) to Lauraceae and Myrtaceae, in a Mixed Ombrophilous Forest fragment, in São João do Triunfo, Paraná.

Segundo Schneider e Schneider (2008), o processo fisiológico responsável pelo crescimento das árvores é afetado diretamente por inúmeros fatores, como disponibilidade de luz, temperatura, água, nutrientes, $\mathrm{CO}_{2}$ e conteúdo de clorofila, sendo que a disponibilidade de cada um desses elementos para cada árvore e consequentemente para cada espécie depende da concorrência que ocorre dentro da floresta 
entre os indivíduos. Esse fato é difícil de ser analisado precisamente em nível de floresta e, até mesmo, para uma família botânica como um todo, devendo haver estudos mais detalhados e em períodos mais longos que permitam melhor compreender os fatores que influenciam na ecologia e no crescimento de cada espécie dentro desse fragmento de Floresta Ombrófila Mista.

\section{CONCLUSÃO}

- A simulação do crescimento em número de árvores e área basal pela razão de movimentação para os anos de 2013, 2015, 2017 e 2019 nesse fragmento de Floresta Ombrófila Mista mostrou que a floresta como um todo crescerá consideravelmente em área basal, mas não em número de árvores, conferindo amadurecimento a esse fragmento.

- As projeções para as quatro espécies e as duas famílias botânicas indicam particularidades distintas entre si para os próximos 8 anos, devendo ser analisadas individualmente.

- No geral, o padrão das distribuições diamétricas para a floresta, para as famílias botânicas e para as espécies de maior valor de importância manter-se-á decrescente, com desaceleração gradual em todos os anos projetados, padrão das florestas multiâneas e mistas.

- Os modelos de prognose do número de árvores por classe de diâmetro mostraram-se de fácil aplicação e com boas estimativas. Sugere-se que, para os anos de 2013, 2015, 2017 e 2019, seja efetuada a comparação e validação das prognoses do número de árvores estimadas neste trabalho, com o intuito de covalidar o modelo de razão de movimentação na utilização de prognoses para planos de manejo sustentável em Floresta Ombrófila Mista.

\section{REFERÊNCIAS}

ASSMANN, E. The principles of forest yield: studies in the organic production, structure, increment and yield of forest stands. Braunschweig: Pergamon Press, 1970. 506 p.

BOM, R. P. Proposição de um sistema de manejo para floresta nativa objetivando a sustentabilidade da produção. 199 f. Tese (Doutorado em Engenharia Florestal) - Setor de Ciências Agrárias, Universidade Federal do Paraná, Curitiba, 1996.

CANAlEZ, G. G.; DALlA CORTE, A. P.; SANQUETTA, C. R. Dinâmica da estrutura da comunidade de lauráceas no período 1995-2004 em uma Floresta de Araucária no sul do estado do Paraná, Brasil. Ciência Florestal, v. 16, n. 4, p. 357 - 367, 2006.

CANETTI, A.; RUY, C. C.; MATTOS, P. P.; BRAZ, E. M. Dinâmica de crescimento de espécies de um remanescente de Floresta Ombrófila Mista em Colombo, PR. Pesquisa Florestal Brasileira. v. 34, n. 77, p. 31 - 37, 2014.

CARVALHO, P. E. R. Espécies arbóreas brasileiras. v. 4. Brasília: Embrapa Informação Tecnológica; Colombo: Embrapa Florestas, 2010. 644 p.

DALLA LANA, M. Dinâmica e prognose do crescimento em um fragmento de Floresta Ombrófila Mista no sul do Paraná. 182 f. Dissertação (Mestrado em Engenharia Florestal) - Universidade Federal do Paraná, Curitiba, 2013.

EBLING. A. A. Dinâmica e projeção diamétrica em remanescente de Floresta Ombrófila Mista na Flona de São Francisco de Paula, RS. 126 f. Dissertação (Mestrado em Engenharia Florestal) Universidade Estadual do Centro-Oeste, Irati, 2012.

EMPRESA BRASILEIRA DE PESQUISA AGROPECUÁRIA (EMBRAPA). Centro Nacional de Pesquisa de Solos. Sistema Brasileiro de classificação de solos, 2. ed. Rio de Janeiro: Embrapa Solos, 2006. 296 p.

FISCHER, G. R. Manejo sustentado de florestas nativas. Joinvile, 1987. 82 p. 
HOSOKAWA, R. T.; MOURA, J. B.; CUNHA, U. S. Introdução ao manejo e economia de florestas. Curitiba: Editora da UFPR, 1998. 162 p.

HUSCH, B.; MILLER, C. I.; BEERS, T. W. Forest Mensuration. 3 ed. New York: Wiley, 1982. 402 p. INSTITUTO AGRONÔMICO DO PARANÁ (IAPAR). Cartas climáticas do Estado do Paraná. Disponível em: <http://www.iapar.br/modules/conteudo/conteudo.php?conteudo=677>. Acesso em: $11 / 03 / 2012$.

KLEIN, R. M. Importância sociológica das mirtáceas nas florestas rio-grandenses. In: CONGRESSO NACIONAL DE BOTÂNICA, 34., 1984, Manaus. Anais... Manaus: Sociedade Botânica do Brasil, 1984. p. $367-375$.

MACHADO, S. A.; AUGUSTYNCZIK, A. L. D.; NASCIMENTO, R. G. M.; FIGURA, M. A.; SILVA, L. C. R.; MIGUEL, E. P.; TÉO, S. J. Distribuição diamétrica de Araucaria angustifolia (Bert.) O. Ktze. em um fragmento de Floresta Ombrófila Mista. Scientia Agraria, Curitiba, v. 10, n. 2, p. 103 - 110, 2009.

SANQUETA, C. R.; MATTEI, E. Perspectiva de recuperação e manejo sustentável das Florestas de Araucária. Curitiba: Multi-Graphic Gráfica e Editora, 2006. 264 p.

SCHAAF, L. B.; FIGUEIREDO FILHO, A.; SANQUETTA, C. R.; GALVÃO, F. Incremento diamétrico e em área basal no período de 1979-2000 de espécies arbóreas de uma Floresta Ombrófila Mista localizada no Sul do Paraná. Floresta, Curitiba, v. 35, n. 2, p. 271 - 290, 2005.

SCHNEIDER, P. R.; FINGER, C. A. G. Manejo sustentado de florestas inequiâneas heterogêneas. Santa Maria: UFSM, 2000. 195 p.

SCHNEIDER, P. R.; SCHNEIDER, P. S. P. Introdução ao manejo florestal. 2. ed. Santa Maria: FACOS-UFSM, 2008. 566 p.

SCHNEIDER, P. R. Manejo Florestal: planejamento da produção florestal. Santa Maria: CEPEF/FATEC, 2009. $613 \mathrm{p}$.

SCOLFORO, J. R. S.; PULZ, F. A.; MELLO, J. M.; OLIVEIRA FILHO, A. T. Modelo de produção para floresta nativa como base para manejo sustentado. Cerne, Lavras, v. 2, n. 1, p. 112 - 137, 1996.

SCOLFORO, J. R. S. Manejo Florestal. Lavras: UFLA/FAEPE, 1998. 438 p.

STEPKA, T. F.; DIAS, A. N.; FIGUEIREDO FILHO, A.; MACHADO, S. A.; SAWCZUK, A. R. Prognose da estrutura diamétrica de uma Floresta Ombrófila Mista com os métodos Razão de Movimentos e Matriz de Transição. Pesquisa Florestal Brasileira (Online), v. 30, n. 64, p. 327 - 336, 2010. 